\title{
Üniversal vitiligoda monobenzileter hidrokinon: Bir olgu sunumu
}

\author{
Monobenzylether of hydroquinone in universal vitiligo: A case report
}

\section{Özet}

Vitiligo deride melanosit yıkımı ile seyreden bir hastalıktır. Vücudun \%80'inden fazla alanında depigmentasyonun gözlendiği tip universal vitiligo olarak adlandırımaktadır. Bu hastalarda normal deri alanının renk açıcı tedavilerle açılması da bir tedavi seçeneğidir. Burada, universal vitiligolu bir hastada monobenzil eter hidrokinon (MBEH) ile alınan başarılı sonuç sunulmaktadır. (Türkderm 2013; 47: 243-5)

Anahtar Kelimeler: Vitiligo, monobenzil eter hidrokinon (MBEH)

\section{Summary}

Vitiligo is a disease characterized by destruction of melanocytes in the skin. Universal vitiligo is a rare type of vitiligo in which $80 \%$ of the body is depigmented. Depigmenting normal skin areas with depigmenting agents is one of the treatment options. Here, we present the case of a patient with universal vitiligo who was successfully treated with monobenzylether of hydroquinone. (Turkderm 2013; 47: 243-5)

Key Words: Vitiligo, monobenzyl ether of hydroquinone (MBEH)

\section{Giriş}

Vitiligo deride melanosit yıkımı ile seyreden bir hastalıktır. Prevalansı \%1-4 arasında değişmektedir¹. Etyopatogenezi tam olarak bilinmemekle birlikte nöral, genetik, otoimmun ve biyokimyasal faktörler üzerinde durulmaktadır2. Ayrıca alopesi areata, tiroid hastalıkları, jüvenil diyabet, pernisiyöz anemi ve Addison hastalığı gibi birçok otoimmun hastalıkla da ilişkilidir3. Vitiligo klinik olarak, lokalize, generalize, üniversal ve miks tipte görülebilir. Vücudun $\% 80$ inden fazla alanda depigmentasyonun gözlendiği tip universal vitiligo olarak adlandırılmaktadır ${ }^{4}$.

Burada, sadece yüzde normal deri alanının kaldığı ve görünümü nedeniyle oldukça sorun yaşayan universal vitiligolu bir hastada monobenzil eter hidrokinon (MBEH) ile alınan başarılı sonuç sunulmaktadır.

\section{Olgu}

Kırk bir yaşında erkek hasta yüzünde bulunan kahverengi ve beyaz lekeler nedeniyle kliniğimize başvurdu. Özgeçmişinde 15 yıldan beri vitiligosu mevcuttu. Soygeçmişinde ise, dedesinde vitiligo olduğu öğrenildi. Altı yıl önce beş ay süre ile PUVA (Psoralen+UVA) tedavisi almış olan hastanın tedavisi normal deri ile lezyonlu deri arasındaki kontrast farkının artması ve tedaviye yanıtının olmaması üzerine kesilmişti. 2006 yılından itibaren yüzde mevcut hiperpigmente alanların tedavisi için, kimyasal peeling (glikolik asid ve triklorasetik asid), Kligman formülü, topikal hidrokinon, tretinoin kullanılmış ve yanıt alınamamıştı.

Yapılan dermatolojik muayenesinde, vücudu tamamen depigmente olan hastanın yüzünde adacıklar halinde hiperpigmente maküler sağlam deri alanları bulunmaktaydı (Resim 1a, 1b, Resim 2). 
Hastanın yüzündeki görünüm nedeniyle yaşam kalitesi bozulmuştu ve sosyal hayatında dış görünümünden dolayı ciddi psikolojik problemler yaşamaktaydı. Yapılan biyokimyasal tetkiklerinde karaciğer ve böbrek fonksiyon testleri normaldi, hemogramı normal sınırlardaydı. Eşlik edebilecek otoimmun hastalıklar açısından bakılan kan B12 vitamin düzeyi ve folik asit değerleri normal idi. Tiroid fonksiyon testlerinde ise herhangi bir patoloji saptanmadı. Hastaya monobenzil eter hidrokinon tedavisi başlandı ve günde iki kez uygulama ile üç ay sonunda >\%75 oranda başarılı yanıt elde edildi (Resim 3a, 3b, Resim 4).

\section{Tartışma}

Vitiligo tedavisinde günümüzde birçok tedavi seçeneği bulunmaktadır. Topikal tedaviler vitiligo tedavisinde önemli bir yer tutmaktadır. Bu tedaviler arasında steroid içeren kremler, kalsinörin inhibitörleri, D vitamini analogları (kalsipotriol), pseudokatalaz yer almaktadır 5 . Universalis tipinde ise, tedavide rezidüel pigmente alanların depimentasyonu gündeme gelmektedir .

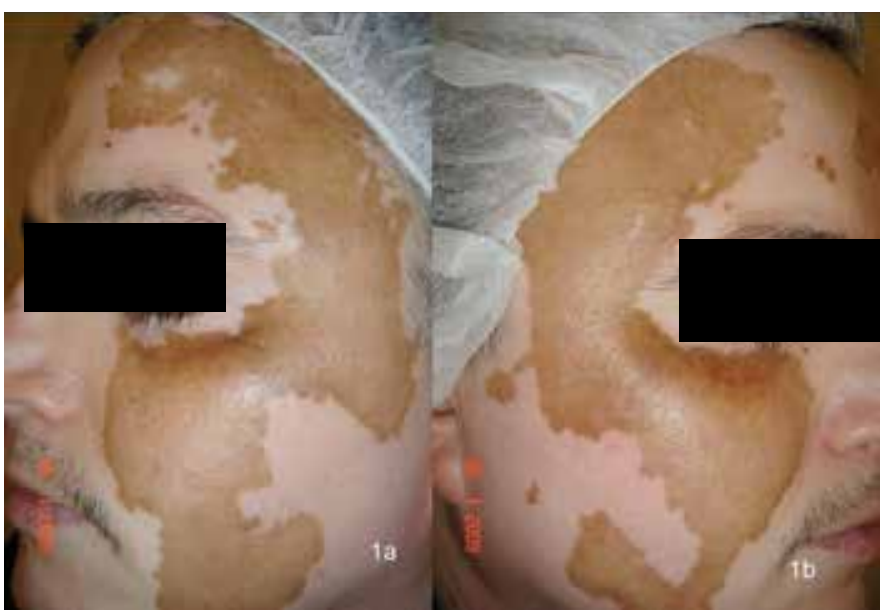

Resim 1-a,b. Hastanın MBEH tedavisi öncesi görünümü

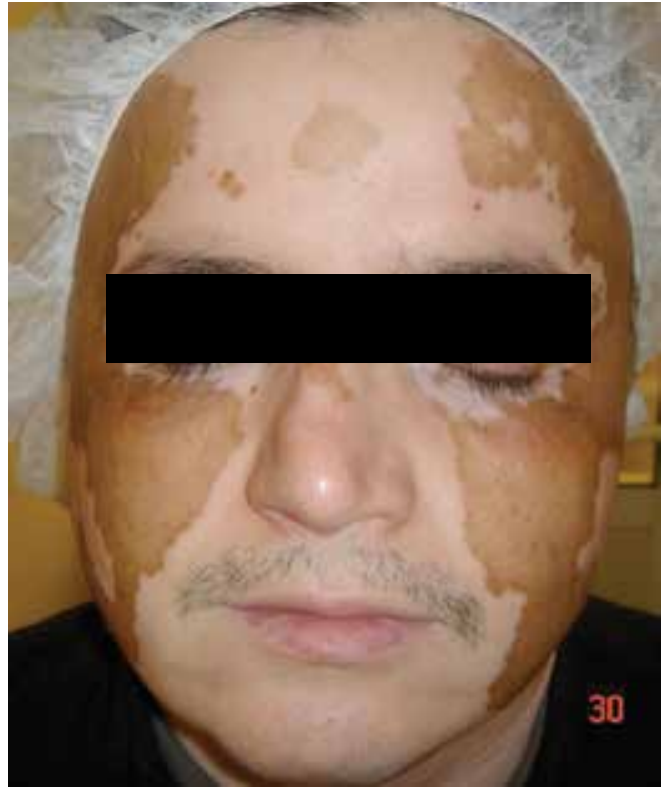

Resim 2. Hastanın MBEH tedavisi öncesi görünümü
Depigmentasyon tedavisinde hasta seçimi önemli bir faktördür. Vücudunda $>\% 50$ 'den fazla pigment kaybı olan ya da yüz ve el gibi kozmetik açıdan hassas bölgelerdeki lezyonları olan hastalar için iyi bir seçim olabileceği belirtilmektedir ${ }^{1}$. Monobenzil eter haricinde, kullanılmakta (4-metoksi fenol) ve deneme aşamasında olan birçok depigmente edici ajan tedavileri mevcuttur. Bunlardan bazılar monometil eter hidrokinon, \%88 fenol solüsyon, lazer ve kriyoterapi gibi tedavi seçenekleridir. Ayrıca imatinib, "imikuimod" gibi birçok ilaç, deneme aşamasında olan potansiyel depigmente edici ajanlar arasında yer almaktadır ${ }^{1}$

Bunlardan monobenzileter hidrokinon (\%10-20) en sık kullanılan ve başarılı sonuçlar alınan bir depigmente edici ajandır. MBEH tirozinazı kompetetif olarak inhibe ederek, melanize melanozomların sayısını azaltarak ve melanosit organel lizisine neden olarak etki etmektedir2. Vitiligo dışında melazma, solar lentigo gibi pigmenter hastalıkların tedavisinde de kullanılabilmektedir2,5,6,7.

Vitiligoya yaklaşım ile ilgili yayınlanan bir kılavuzda MBEH tedavisinin seçilmiş olgularda, yüz ve eller gibi kozmetik açıdan önemli alanlarda

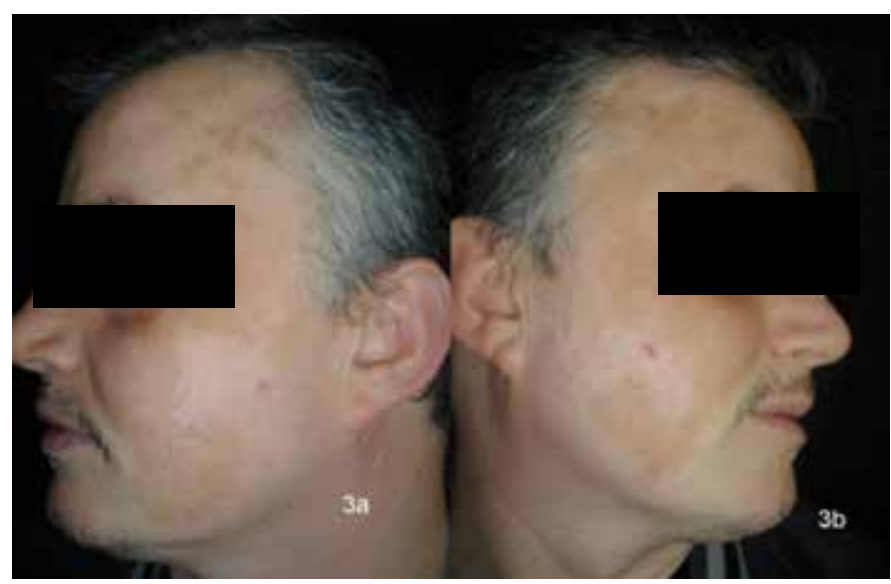

Resim 3-a,b. Hastanın MBEH tedavisi sonrası görünümü

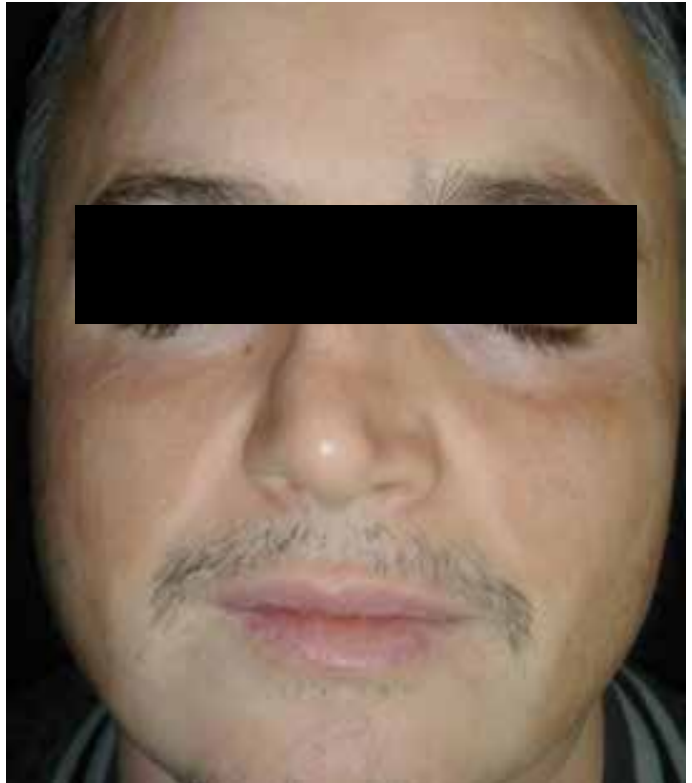

Resim 4. Hastanın MBEH tedavisi sonrası görünümü 
uygulanması gerektiği ve bu tedavinin kanıt düzeyinin 4 olduğu bildirilmektedir. Vitiligoda depigmentasyon tedavisi ile ilgili literatürde randomize kontrollü çalışma bulunmamaktadır. Var olan yayınlar olgu serileri, konsensus bildirileri şeklindedir6. On sekiz vitiligo hastası ile yapılan çalışmada, \%20'lik MBEH uygulanması ile, sekiz hastada tam depigmentasyon elde edilirken, üç hastada ise herhangi bir etki gözlenememiştir?

Hastalarda \%20'lik konsantrasyonun 3-4 ay boyunca kullanılması ile depigmentasyon sağlanmaması durumunda \%40'a kadar konsantrasyon arttırabilmektedir. Sık görülen yan etkileri arasında irritasyon, kontakt dermatit yer almakla birlikte ekzojen okronozis, MBEH direnci de bildirilmektedir. Genellikle oluşan depigmentasyon irreversibl olmasına rağmen güneş ışınlarına fazla maruziyet sonrası yeniden pigmentasyon gelişimi de gözlenebilmektedir ${ }^{1}$.

Universal vitiligoda sadece sınırlı alanda normal deri alanının kalması nedeniyle yaşam kalitesi olumsuz etkilenebilmektedir? ${ }^{7}$ Vitiligolu hastalarda psikiyatrik semptomlar üzerine yayınlanan bir makalede \%10 depresyon, \%7-9 distimi, \%18-22 depresif epizodlar, \%10 intihar düşünceleri, \%3,3 intihar girişimleri ve yine aynı oranda anksiyete bulgularının gözlendiği bildirilmiştir8.

Sonuç olarak vitiligo, hastaların yaşam kalitesini büyük ölçüde etkileyebilen bir hastalıktır. Her ne kadar kozmetik bir problem olarak ele alınsa da, yol açtığı psikososyal etkiler göz ardı edilmemelidir8. Vitiligo tedavisinde değişik tedavi seçenekleri yer almakla birlikte monobenzil eter hidrokinon depigmente edici tedaviler arasında etkili bir tedavi seçeneğidir. Olgumuzda da monobenzil eter hidrokinon tedavisi üç ay gibi kısa bir sürede belirgin derecede etkili bulunmuş ve hastanın yaşam kalitesini olumlu etkilemiştir. Bu ilacın ülkemizde bulunmaması hastaların ilaca ulaşmasını olumsuz yönde etkilemekte ve etkili olmayan diğer tedavilerin kullanılması da zaman kaybına yol açmaktadır.

\section{Kaynaklar}

1. Alghamdi K, Kumar A: Depigmentation therapies for normal skin in vitiligo universalis. J Eur Acad Dermatol Venereol 2010.

2. Denli $Y G$, Acar MA, Sönmezoğlu MS, Yücel A: Vitiligo. Ed. Tüzün $Y$, Gürer MA, Serdaroğlu S, Oğuz O, Aksungur VL. Dermatoloji 3.baskı, İstanbul, Nobel, 2008;1465-90.

3. Lotti T, Berti S, Moretti S: Vitiligo therapy. Expert Opin. Pharmacother 2009; 10:2779-85.

4. Lotti T, Gori A, Zanieri F, Colucci R, Moretti S: Vitiligo: new and emerging treatments. Dermatol Ther. 2008;21:110-7.

5. Hossani-Madani AR, Halder RM: Topical treatment and combination approaches for vitiligo: new insights, new developments. G Ital Dermatol Venereol 2010;145:57-78.

6. Gawkrodger DJ, Ormerod AD, Shaw L, et al: Guideline for the diagnosis and management of vitiligo. Br J Dermatol 2008;159:1051-76.

7. Mosher DB, Parrish JA, Fitzpatrick TB: Monobenzylether of hydroquinone. A retrospective study of treatment of 18 vitiligo patients and a review of the literature. Br J Dermatol 1977;97:669-79.

8. Ongenae K, Beelaert L, van Geel N, Naeyaert JM: Psychosocial effects of vitiligo. J Eur Acad Dermatol Venereol 2006;20:1-8. 